Bangladesh J. Sci. Res. 28(1): 61-72, 2015 (June)

\title{
STREAMLINE SIMULATION STUDY ON RECOVERY OF OIL BY WATER FLOODING: A REAL CASE STUDY ON HARIPUR FIELD
}

Mohammad Amirul Islam*, A.S.M. Woobaidullah and Badrul Imam

Department of Geology, University of Dhaka, Dhaka-1000, Bangladesh

\begin{abstract}
Haripur field is the first oil producing field in Bangladesh. The field produced approximately 0.53 MMSTB of oil from the well No. SY-7. The oil production began in 1987 and terminated in 1994. All of the oil was produced by the reservoir own energy from the depth of 2030 meter. Recent investigation and study have revealed that approximately 31 MMSTB Oil is remaining in that formation as validated by the reservoir performance based study i.e. oil production rate and tube head pressure history matching. At present condition, the reservoir has no pressure energy to lift the oil to surface as it requires minimum 1500 psi pressure, so it needs pressure energy to lift the oil to surface. Among the recent developed technologies water injection is one of the best methods to sweep oil towards the production well from the injection well as well as to provide sufficient pressure for lifting. In this study we proposed design for optimum waterflooding pattern and defined optimum number of injection and production wells. In addition the production and injection rates are optimized along with selection of the best placement of production and injection wells and their life.
\end{abstract}

Keywords: Reserve and resources, Water flooding, Streamline simulation.

\section{Introduction}

The Haripur field is located about $230 \mathrm{~km}$ north-east of Dhaka and $18 \mathrm{~km}$ from Sylhet town, which lies between Shillong Plateau in the North and Tripura High in the South. Geologically Tripura High corresponds to a folded system of Tertiary formations that plunge southward underneath the recent alluvium of the Surma river. The field produced 0.53 million barrel of stock tank oil and simulation study revealed that the filed has more 31 million barrel of oil remaining in the Bhuban Formation (www.sgfl.org.bd).

The petroleum resources management system (PRMS) regarding the application of three broad categories of deterministic analytical procedures for estimating the range of recoverable quantities of oil and gas are using (a) analogous methods, (b) volumetric methods, and (c) production performance analysis methods. During exploration, appraisal, and initial development periods, resource estimates can be "indirectly" derived only by estimating original in-place volumes using static-data-based volumetric methods and the associated recovery efficiency based on analog development projects, or using analytical methods. In the later stages of production, recoverable volumes can also be estimated "directly" using dynamic-data-based production performance analysis. In the scenario approach, three separate analyses are prepared to bracket the uncertainty through sensitivity analysis (i.e., estimated values by three plausible sets of key input

*Corresponding author: <mohamm1978@gmail.com>. 
parameters of geoscience and engineering data). These scenarios are designed to represent the low, the best (qualitatively considered the most likely) and the high realizations of original in-place and associated recoverable petroleum quantities. Depending on the stage of maturity, these scenarios underpin the PRMS categorization of reserves (1P, 2P, and 3P) and contingent resources (1C, 2C, and $3 \mathrm{C}$ ) of the projects applied to discovered petroleum accumulations, or prospective resources (low, best, and high) of the undiscovered accumulations with petroleum potential. The resources classification entirely depends on the recovery methods and implemented projects(www.spe.org).

Waterflooding is a common secondary oil recovery process in which water is injected into an oil bearing reservoir using strategically placed injectors so as to maintain pressure and sweep oil to adjacent production wells (Aronofsky et al. 1958). In our work, we evaluated the long-term (generally 5 to 15 years) waterflooding, given a cumulative target limit of the total field injection volume. The goal is to determine (near) optimal individual well rates that are sustainable (subject to constraints, such as gradual changes over time as well as globally maximum/minimum total fluid rate handling capacities). To reduce the computational costs, we made use of streamlinederived information to drive the well rate changes while also taking advantage of the computational efficiency of streamline simulation itself, which is generally well-suited for modeling waterfloods.

\section{Filed description}

The Sylhet structure was delineated by Pakistan Petroleum Limited (PPL) after recording single fold seismic data. Gas was discovered in 1955 by drilling Sylhet-1 well, which was the first gas discovery well in Bangladesh. Unfortunately the well blew out leaving a crater. Subsequently five more wells, Sylhet-2 to Sylhet-6, were drilled during the period from 1956 to 1964. Sylhet-4 blew out upon reaching $315 \mathrm{~m}$ and Sylhet-5 was drilled in 1963 as an observation well up to a depth of $575 \mathrm{~m}$. Sylhet-6 was drilled in 1964 up to a depth of $1,405 \mathrm{~m}$ and was completed as a dual producer. Sylhet-7 was drilled in 1986 as a gas development well but turned out to be the first oil discovery well. Surma-1 and the sidetracked well Surma-1A were drilled in 1989 to appraise the oil discovery (www.sgfl.org.bd).

\section{Reservoir simulation model}

A reservoir simulation model characterizes the reservoir by integrating the static geological model and the dynamic flow model populated with actual reservoir performance data such as pressures, tests, production rates, inter fluid-rock characteristic curves characterized by the capillary and relative permeability curves, PVT data, etc. (Caers et al. 2002).There are geocellular reservoir model of static reservoir condition and conventional, compositional, thermal and streamline reservoir simulation model of dynamic reservoir condition (Aziz and Settari 1979).

The structural model has been constructed by 94 cells $\times 83$ cells $\times 74$ cells in I,J and $\mathrm{K}$ directions, altogether 577348 grid cells among them Bhuban Formation is in from 69 to 74 simulation layers where 31 MMSTB of oil remains as depicted by Fig.1. 


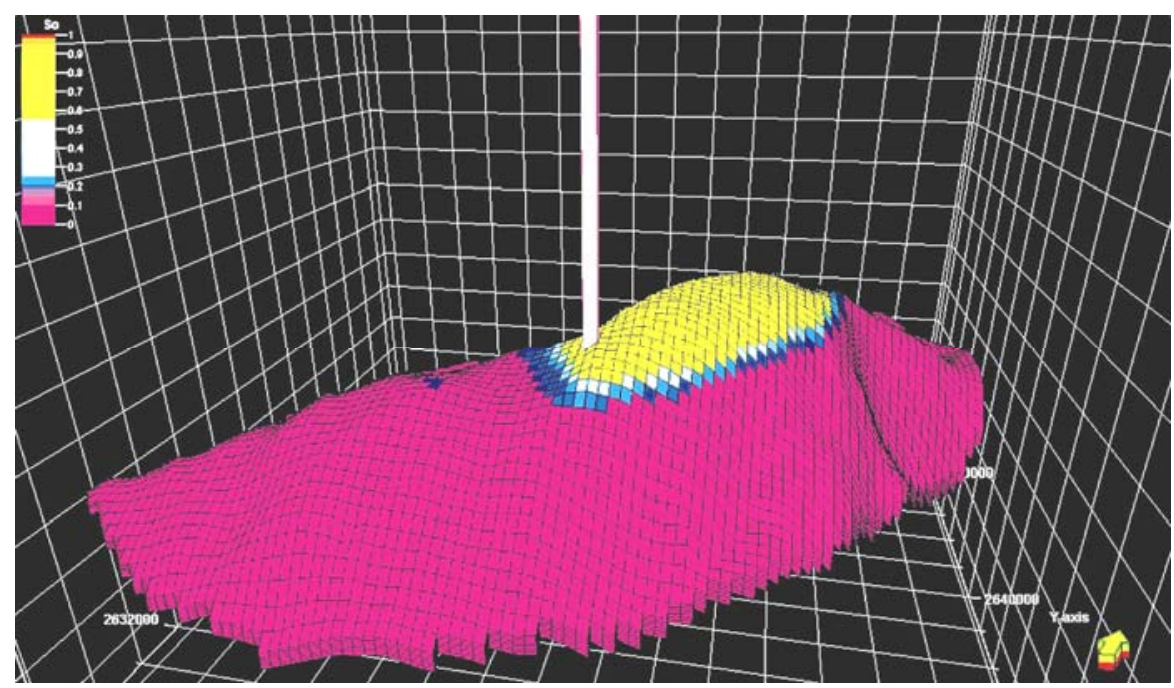

Fig. 1. Reservoir simulation model and position of oil zone.

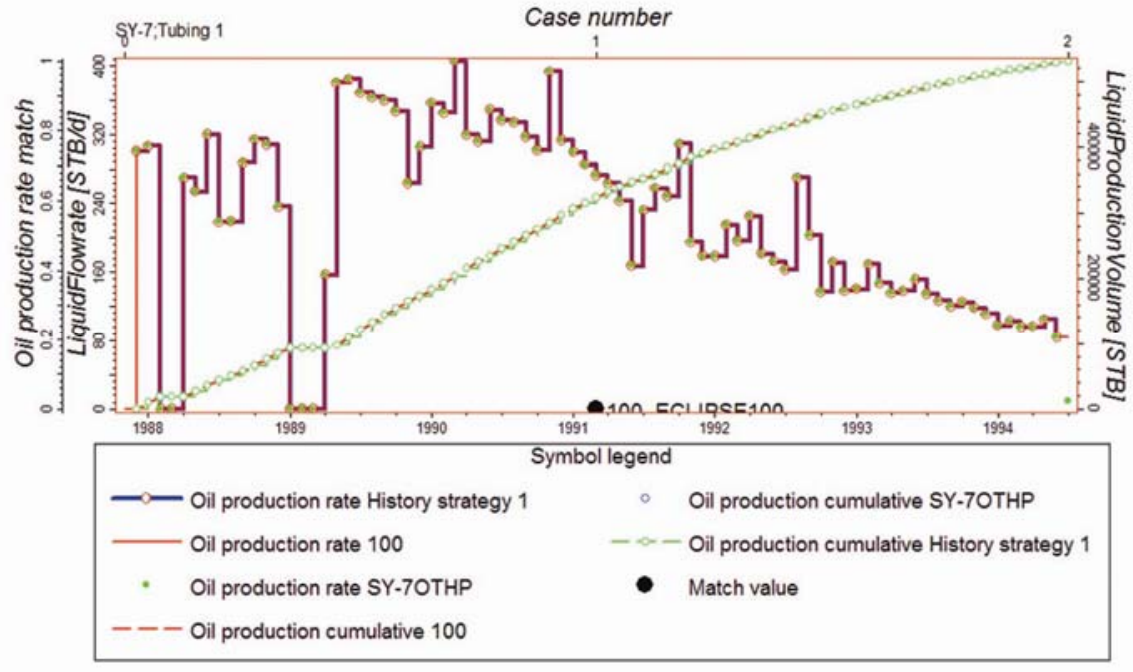

Fig. 2. History matching of oil production rate of well no. SY-7 and cumulative oil production.

\section{Resources estimation and classification}

Developing a meaningful reservoir model capable of generating reliable results with reasonable certainty requires a multidisciplinary team with appropriate technical skills and broad experience. Once a reasonably good history match is obtained, the model can be used to predict production and injection profiles, infill wells, well workovers, stimulation, and other requirements according to specified prediction guidelines (related to drilling, well completions, production engineering and reservoir management, including vertical flow and surface flow systems) under various "whatif" conditions for reservoir development, production and management strategies. Based on a 
comparative economic analysis, the optimum development and producing strategy can be selected for implementation. Depending on the amount and quality of performance data available, the projected cumulative production to the economic limit with this optimum strategy should establish the most likely estimated ultimate recovery (EUR).

Table 1. Resources classification framework in 2015.

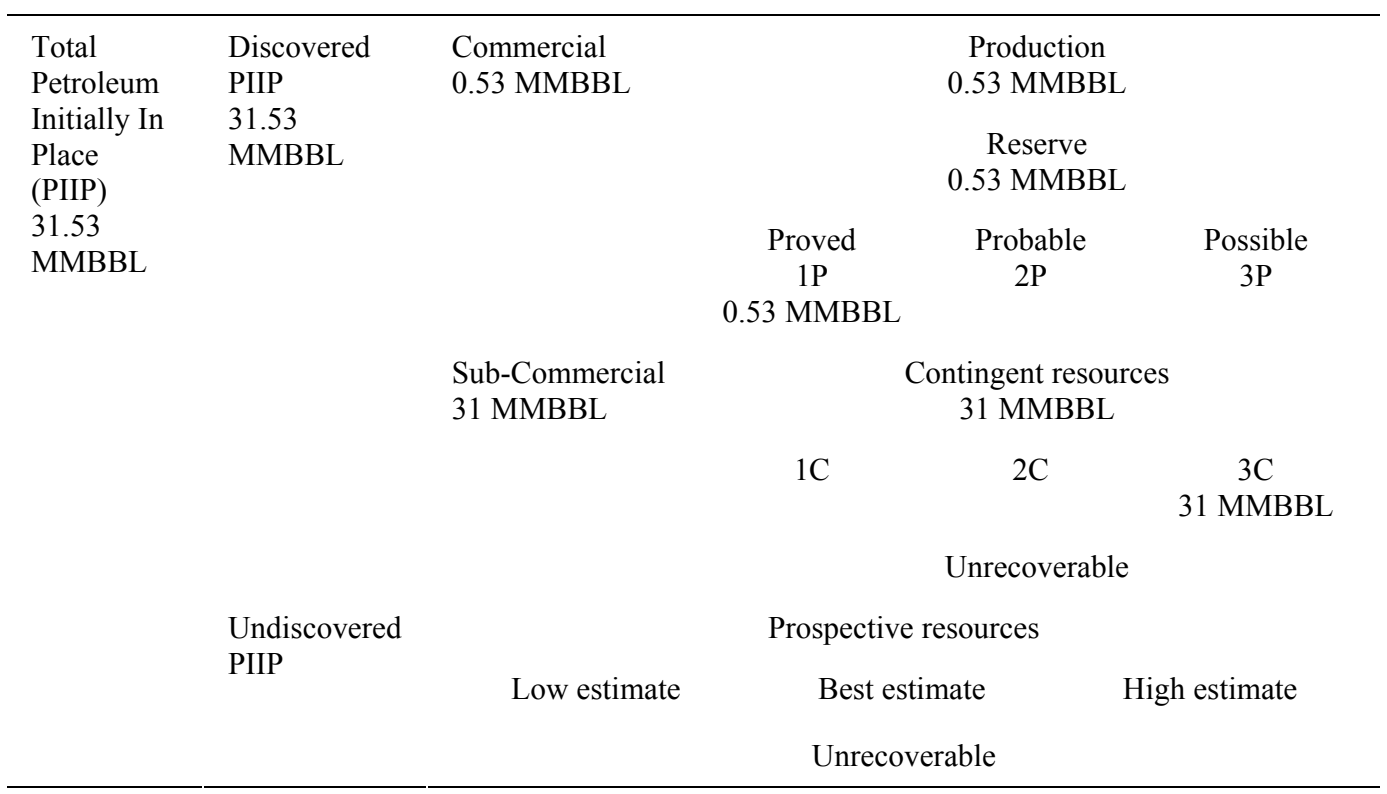

Based on the extensive log, core, and testing data obtained over the past 12 years (discovery year, 2-year appraisal period followed by a 3-year initial development and a 7-year of production periods), a 0.5 million-cell geo-cellular model was built and used to estimate an OIIP of about 31.53 MMSTB. Based on this most likely or best $3 \mathrm{D}$ geological realization (with an OIIP estimate of 31.53 MMSTB), a related integrated 3D and three-phase reservoir simulation model was developed by a multidisciplinary team and used to match this extensive reservoir performance history covering a period of 7 years with 0.53 MMSTB (1.68\% OIIP) produced (Fig. 2). This history-matched black-oil model was used to predict future reservoir performance under the ongoing base-case operations using peripheral waterflood, including economically justified well workovers, infill drilling, and well completions to better manage the decline based on to recover 31 MMSTB of oil remain as contingent resources in 2015 shown in Table 1. In the reservoir position of the well is shown in Fig. 3.

\section{Streamline simulation of production period}

Although reservoir flow simulation is a mature technology, there is a general lack of understanding in the oil and gas industry as to when it should be applied, the limitations of it and how recent technical improvements have changed simulation. Streamline models have 
dramatically changed simulation work and made predictions better. Simple workflow and quality control issues are absolutely critical to insuring reasonable forecasts. Tracing the streamline is the process whereby we create the unique streamline passing through a specified point in 3D space. From this starting point the streamline is traced backward and forward to create the complete streamline. The algorithm is iterative and rests on calculating the exit point in a grid cell given an entry point, repeated until a stop criterion is reached.
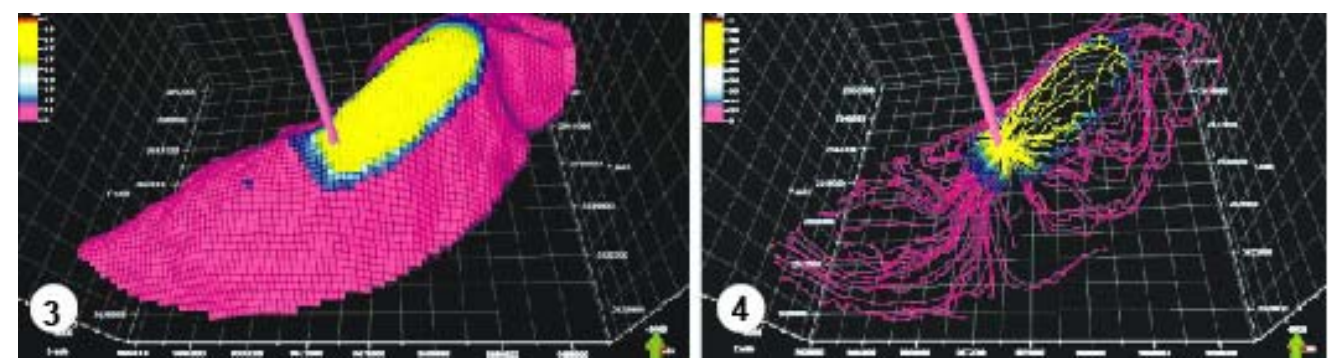

Fig. 3. Position of well no. SY-7 in reservoir producing 0.53 MMSTB of oil. Fig. 4. Oil saturation in streamtubes i.e. oil flow lines through the porous permeable formation.

The flow rate and TOF are defined in points along the streamline and the grid cell pointer is defined for each linear segment between the points defining the streamline. For the grid cell pointer to be unique, there have to be points defined for every grid cell face that the streamline passes through. The streamline generates flow rate, fractional flow rate, saturation attributes providing a better understanding of the reservoir performance inside the porous permeable formation (Batycky et al.1997).

The oil saturation attribute varies from value 0.0 to 1.0 , at the top oil zone where saturation is 0.8 below transition zone saturation is 0.2 further below the saturation is 0.0 where the water zone lays shown in Fig. 4. Streamtubes of oil flow rate are shown in logarithmic scale varies from 0.0001 to 1.00 . In the oil zone the oil flow rate is $0.1 \mathrm{STB} / \mathrm{D}$ and somewhere $0.01 \mathrm{STB} / \mathrm{D}$ depicted in Fig. 5.
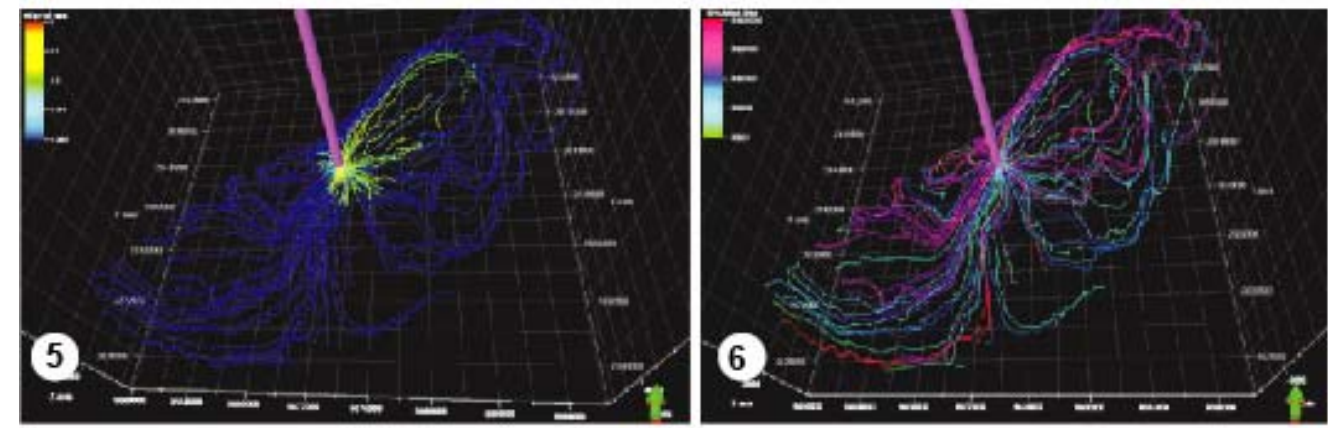

Fig. 5. Oil flow rate in streamtubes i.e. oil flow rate through the porous permeable formation (Capillary tubes). Fig. 6. Time of flight in streamtubes i.e, the time taken by the oil to arrive at production well through the porous permeable formation (Capillary tubes) from the sources. 
Streamline simulation relies on tracing the flow field and then solving the transport of different flow phases along discrete flow paths. Discretization of the flow field leads to construction of stream tubes with each stream tube being associated with a particular flow rate. A streamline can be imagined as the line through the centre of a stream tube. It is inefficient to compute stream tubes for 3D problems.

The time-of-flight (TOF) is a unique property associated with a streamline. At any point on a streamline the TOF is the time taken by a neutral tracer to arrive at that point from a source/injector. Alternatively, TOF can also be defined as the time taken to travel a sink/producer (Batycky et al. 2006). TOF varies from 100 days to 100000 days shown in Fig.6.

Mathematically, it is defined as:

$$
\tau=\int_{0}^{S} \frac{\varphi}{u_{t}} d s
$$

Where, $\tau=$ time of flight, $\varphi=$ porosity, $\mathrm{u}_{1}=$ Darcyvelocity, $\mathrm{s}=$ distance along the stream line

\section{Water flooding}

Streamline simulation is being increasingly used for managing waterflood operations in some of the largest fields in the world. Underpinning the analysis of a waterflood is the relationship between injection and production wells. This relationship can be directly and fully quantified on reservoir models through streamline simulation as is clear from Figs 9-24. This ability of streamline simulation is unique. In the past, engineers have used time consuming trial and error methods to optimize waterflood simulations using streamline data. In this study we discuss the use of the Pattern Flood Management. This option provides an automated way of optimizing streamline waterflood simulations. The techniques currently used are standard reservoir engineering methods.
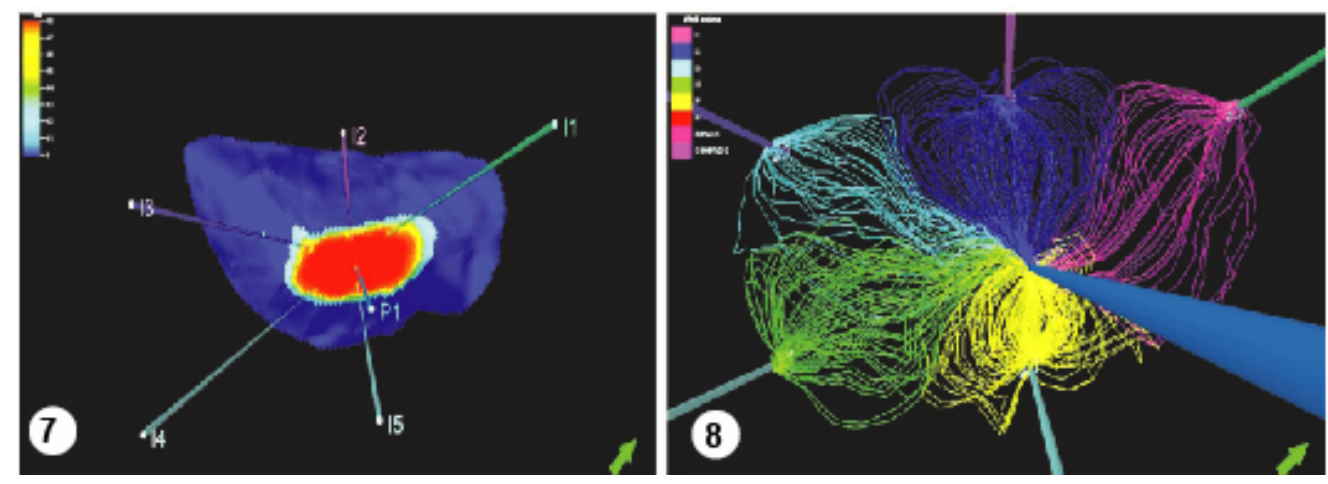

Fig. 7. Injection and production wells. Fig. 8. Injection and production wells index. 
Water injection is a proven technology being used from long past chronologically developed from practical field experiences shows that peripheral water injection is the best method to sweep oil to the production well placed in the crest of the oil zone. Similarly five water injection wells I1, I2, I3, I4 and I5 are placed in near the water oil contact (WOC) and one production well P1 is placed in the peak of the oil zone shown in Fig. 7. Thepinkattribute illustratesfor well index I1, blue attribute for I2, sky attribute for I3, green attribute for I4, yellow attribute for I5 and red attribute for P1shown in Fig. 8.
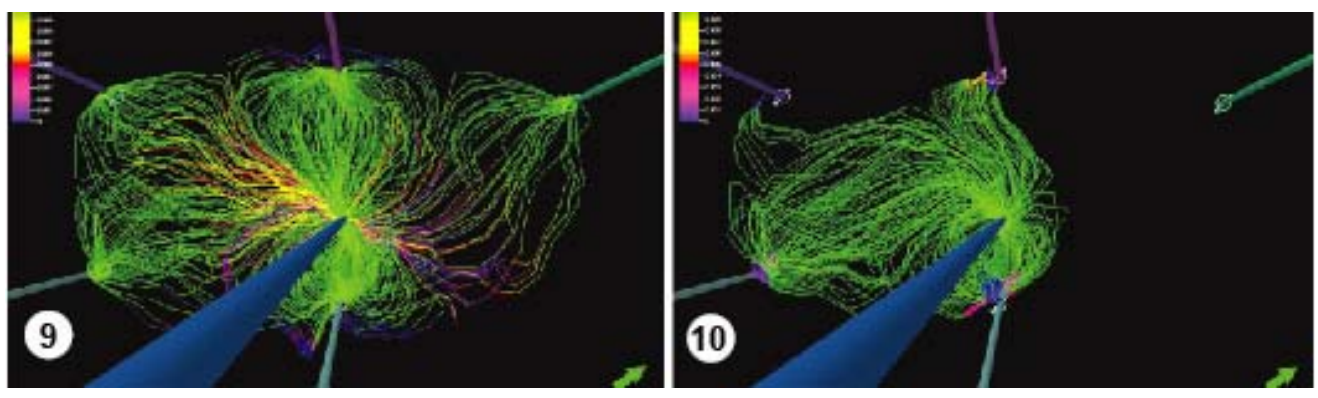

Fig. 9. Oil production rate (STB/D) in 2020. Fig. 10. Oil production rate (STB/D) in 2030.

Streamline flux for oil production rate at the start of water injection developed very well and sharply. Most of the lines show value $0.01 \mathrm{STB} / \mathrm{D}$ by green line with some red, blue and pink lines value 0.005 STB/D, 0.003 STB/D and 0.000 STB/D respectively shown in Fig. 9.

At the end of simulation the streamline flux for oil production rate of water injection wells I2, I3, I4 and I5 remain sharp. All of the lines show value 0.01 STB/D by green line depicted in Fig. 10. The water front is still near the injection wells.
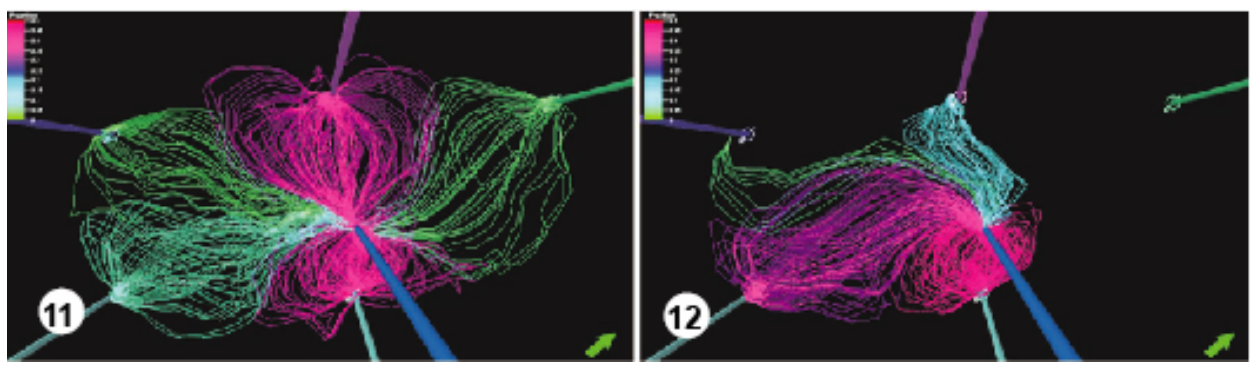

Fig. 11. Fractional flow of oil in 2020. Fig. 12. Fractional flow of oil in 2030.

The fractional flow of oil is the ratio of oil flow rate to the total liquid flow rate. Injection well no. I2 and I5 developed 50\% fractional flow pattern whereas well no. I4 gives $10 \%$ and I3 and I1 provide only $5 \%$ shown in Fig. 11 . As usual I1 ends very shortly and I 2 attains at $15 \%$ with I5 still at 50\%, I3 at 5\% and I4 at 35\% fractional flow pattern in 2030 (Fig. 12). Among the injector wells the 15 swept oil with better efficiency as the formation between I5 and P1 is good porous and permeable. 
Oil saturation flux varies from 0.8 to 0.0 . The streamline of oil saturation is almost 0.8 between injector and the producer at the start of injection (Fig. 13) and by progressing of water injection the oil saturation flux down to 0.6 within ten years (Fig. 14).
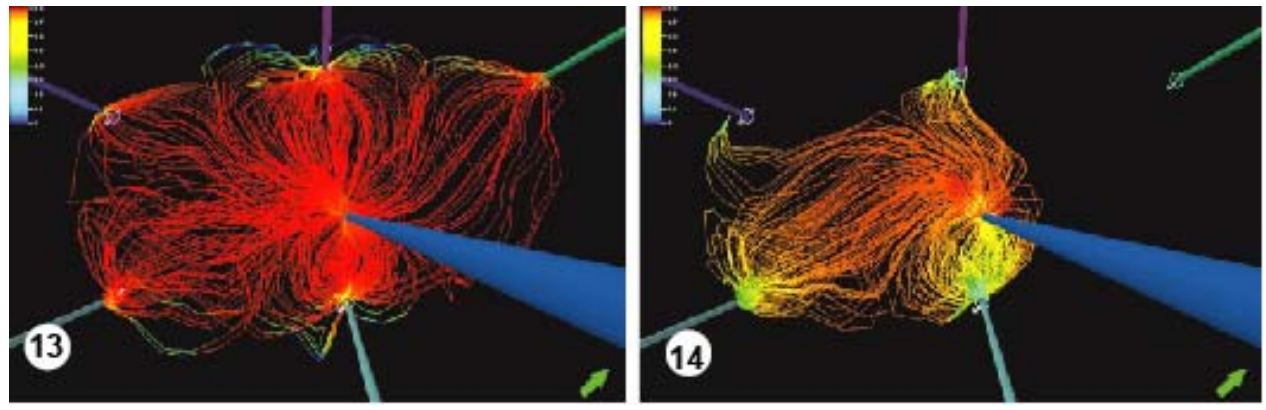

Fig. 13. Oil saturation in 2020. Fig. 14. Oil saturation in 2030.

The time of flight is ranging from 0.0 day to 100,000 days. Natural traces will take time to arrive to producer from injector. To arrive to P1 from I5, I2, I1, I3 and I4 tracer will take 10,000 days, 50,000, 1,00,000, 1,00,000 and 1,00,000 days, respectively shown in Fig. 15. From P1 to arrive to I5, I2, I1, I3 and I4 tracer will take 10,000, 50,000, 1,00,000, 1,00,000 and 1,00,000 days, respectively shown in Fig. 16.
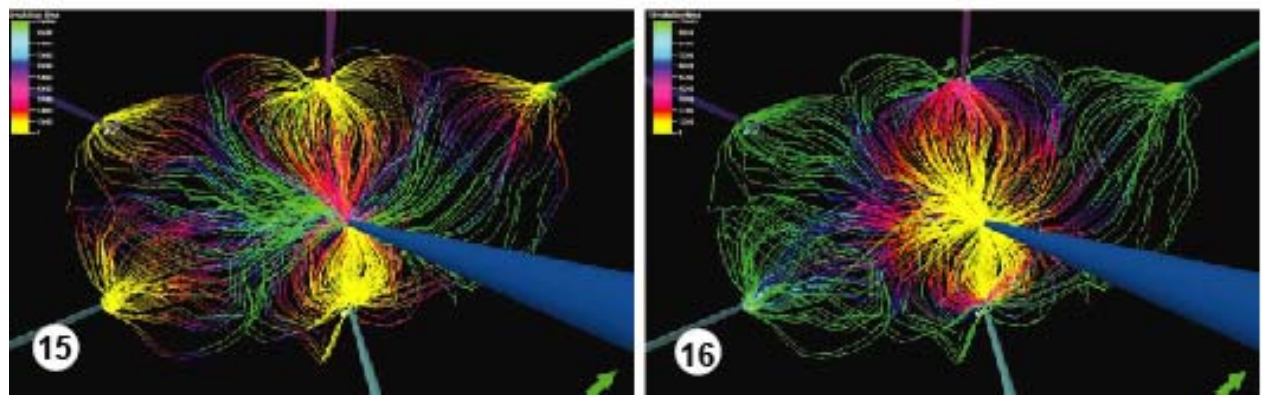

Fig. 15.Time of flight (begin) at 2020. Fig. 16. Time of Flight (end) at 2020.

The time of flight is changing over time. At the end of the injection between injector and producer is ranging from 10,000 to 1,00,000 days depicted in Figs. 17 and 18. Injected water flows through the porous permeable formation with 0.0001 STB/D shown in Fig. 19 at the beginning of injection very near zone of the injector.

At the end of simulation injected water flows through the porous permeable formation with $0.0001 \mathrm{STB} / \mathrm{D}$ shown in Fig. 20 far from the injector indicating water is advancing towards the production well. Water flow stream is leveled by the blue line and the front is indicated by the separation point between blue and yellow color stream. Injector I5 arrived at its breakthrough point whereas others remain far away from breakthrough. The fractional flow of water is defined 
as the ratio of water flow rate to the total liquid flow rate. The fractional flow profile of injectors is shown in Fig. 21 at the start of injection. I2 and I5 start with 50\% flow, I1 and I3 start with 15\% flow and I4 starts with $27 \%$ flow.
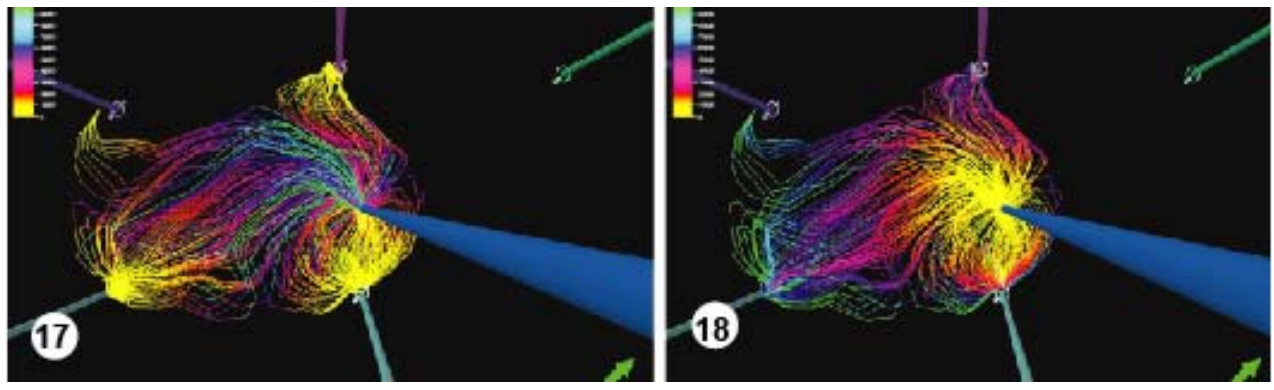

Fig. 17. Time of flight (begin) in 2030. Fig. 18. Time of flight (end) in 2030.

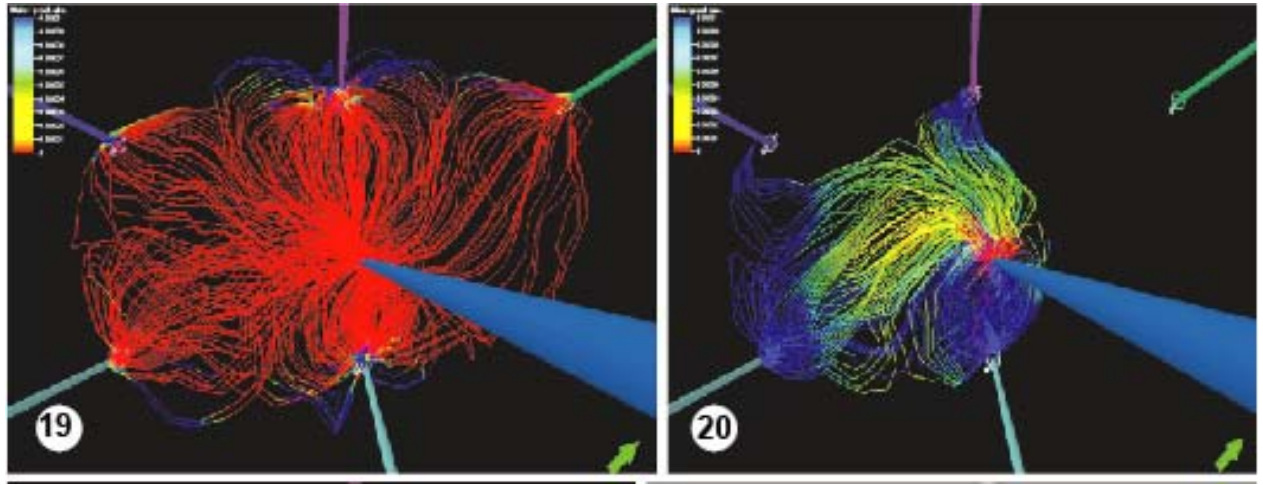

Fig. 19. Injected water flow rate in 2020. 20. Water production rate in 2030.

Fractional water flow of I1 reduces to $0.0 \%$ very soon, I2 down to $10 \%$, I 3 drop to $5 \%$, I 4 improves to $35 \%$ and I5 drop to $40 \%$ depicted by Fig. 22. At the start of injection water saturation attribute presented by yellow lines remains at 20\%, shown in Fig. 23, almost uniform all areas between the injectors and producer.

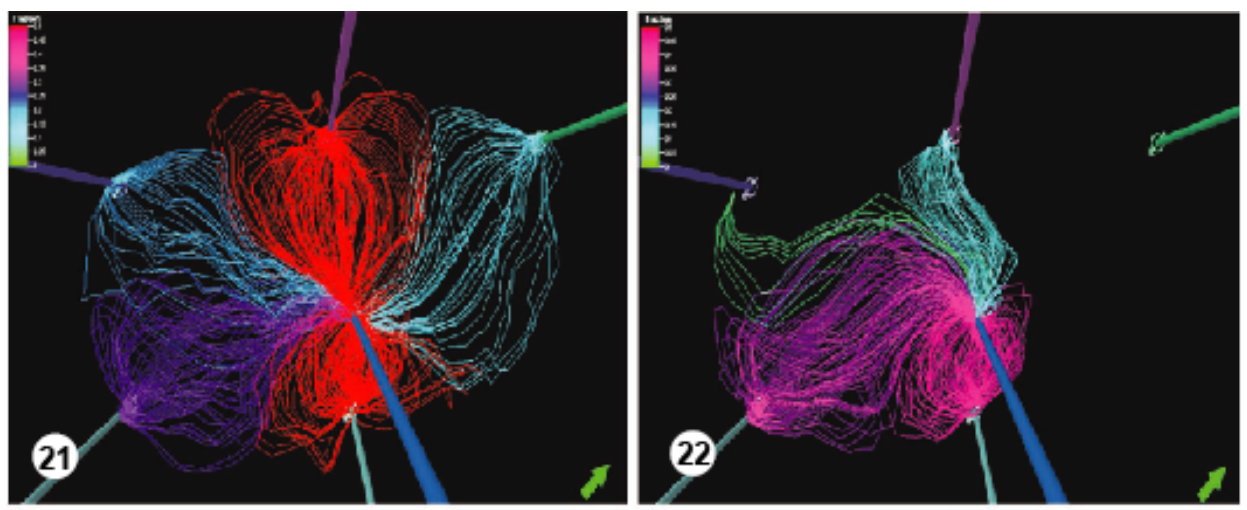

Fig. 21. Water fractional flow in 2020. Fig. 22. Water fractional flow in2030. 

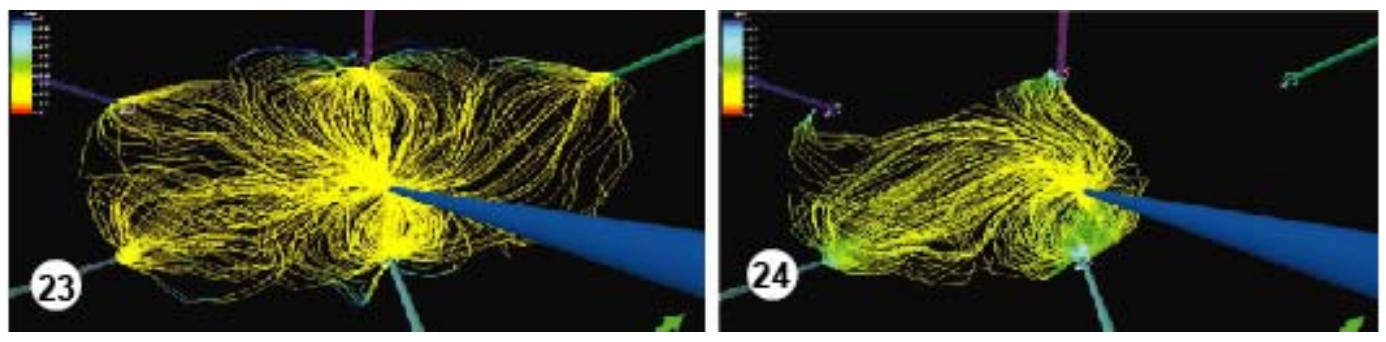

Fig. 23. Water saturation in 2020. Fig. 24. Water saturation in 2030.

Very near zone of the water injectors the water saturation value rises to 70 to $80 \%$ shown by sky color stream line in Fig. 24 indicating almost all oil is swept by the water. Over the forecasted ten years the oil production rate remains content at $460 \mathrm{STB} / \mathrm{D}$ up to 2027 , after that the production is declining to $290 \mathrm{STB} / \mathrm{D}$ and cumulative oil production is $1.66 \mathrm{MMSTD}$, yield $5.3 \%$ recovery shown in Fig. 25. Water injection rate is $200 \mathrm{STB} / \mathrm{D}$ and cumulative injected water is 800000 STB shown in Fig.26.

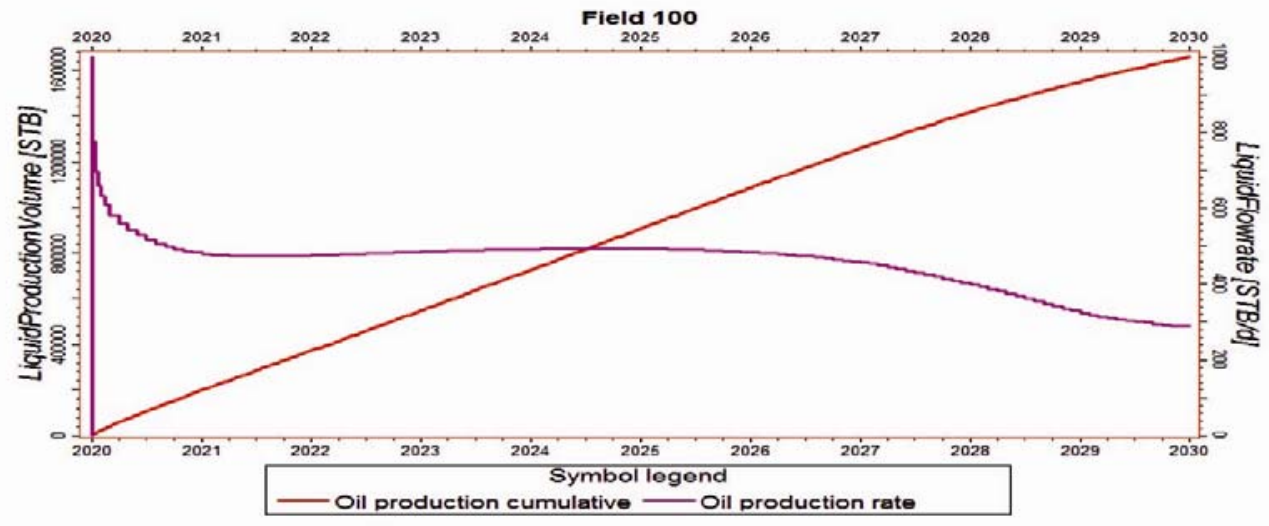

Fig. 25. Oil production rate and cumulative oil production.

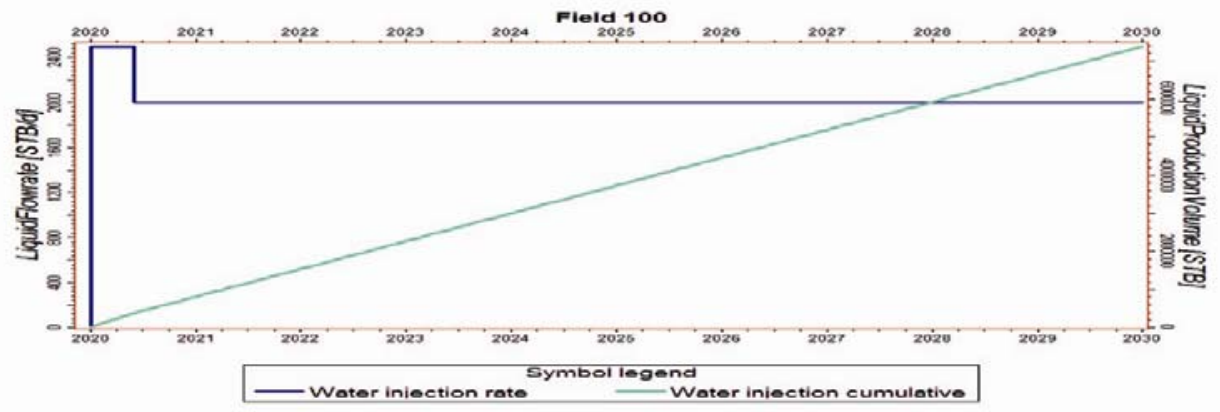

Fig. 26. Water injection rate and cumulative water injection. 


\section{Results}

Among the injection wells well nos. I2 and I5 perform excellent oil displacement efficiency at the start of water injection and the performance sustained constantly. In addition well I4 develops its performance overtime, however well I1 terminates very quickly, within a year. On the other hand well I3 is reduced to $50 \%$. The cumulative oil production is 1.66 MMSTB by injecting 7.38 MMSTB of water. The recovery efficiency is $22.5 \%$ by water injection i.e. to produce $22.5 \mathrm{STB}$ of oil 100 STB water is injected. The field pressure is rising parallel with the quantity of water injected providing pressure energy to the reservoir for future oil production. By the peripheral water flooding technology it is possible to recover oil from the Haripur Field. In 201531 MMSTB contingent resources converted to 31 MMSTB oil reserve at 2020 and 2.19 MMSTB of oil produced and 29.34 MMSTB is possible reserve in 2030. Detail description shown in Table 2.

Table 2. Resources classification framework in 2030.

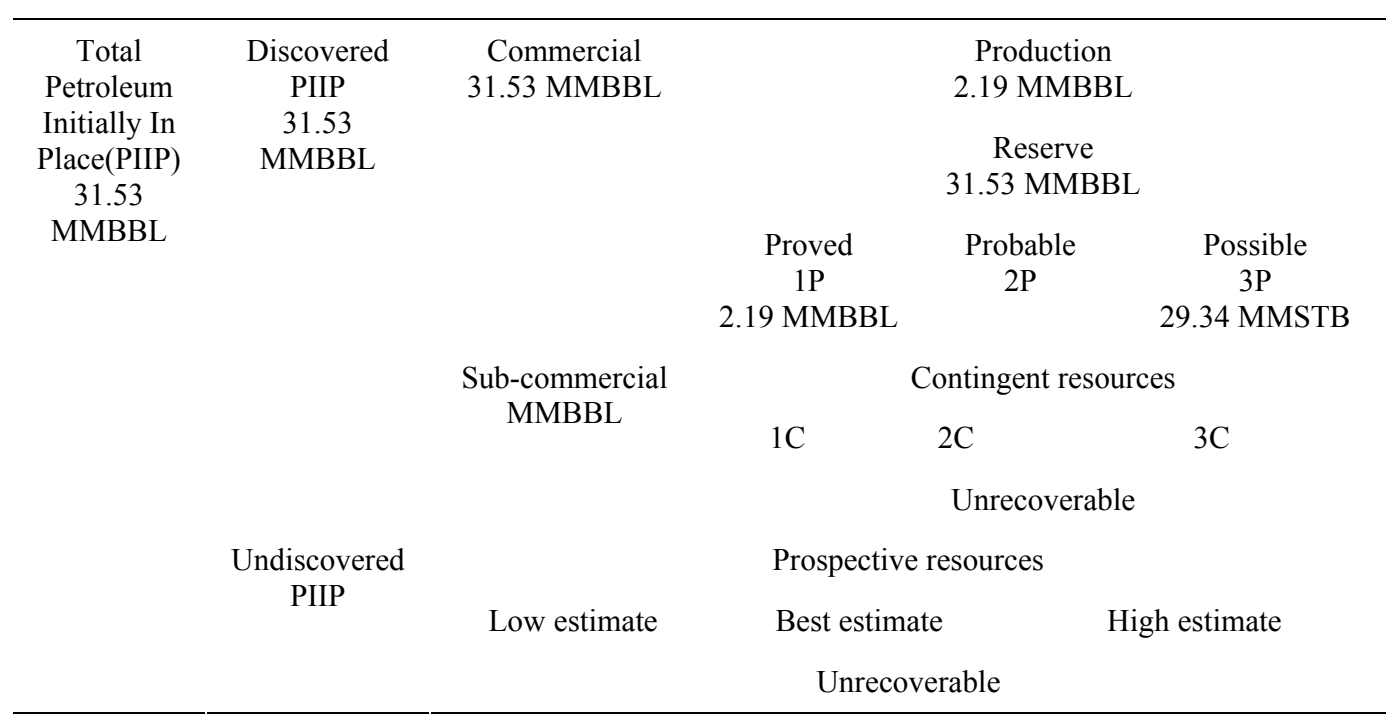

\section{Conclusion}

Oil recovery becomes very challenging with respect to the technical and commercial point of view as uncertainty and risk exist behind the recovery project. It is a good news that invent of several recovery techniques and modeling with very power full computer simulator reduces the uncertainty and risk making the recovery project technically and commercially feasible. In this study, 31 MMSTB of oil remaining in the reservoir after production of 0.53 MMSTB of oil is recoverable by water flooding through five injection and one production wells. It is predicted that 1.66 MMSTB of oil can be recovered by injecting 7.38 MMSTB of water over ten years. It is possible to recover the residual oil also after water flooding by capillary displacement method such as surfactant flooding. 


\section{References}

Aronofsky, J.S., L.Masse, and S.G. Natanson.1958, A model for the mechanism of oil recovery from the porous matrix due to water invasion in fractured reservoirs.Petroleum Transactions, AIME.

Aziz, K. and A. Settari, 1979,Petroleum reservoir simulation.Vol. 476, Applied Science Publishers, London.

Batycky, R.P., M.J. Blunt and M.R. Thiele1997.A 3D field-scale streamline-based reservoir simulator.SPE Reservoir Engineering 12(4): 246-254.

Batycky, R. P., M. R.Thiele, R.O. Baker and S.H. Chugh. 2006. Revisiting reservoir flood-surveillance methods using streamlines. SPEREE 11(2): 387-394.

Caers, J., S. Krishnan, Y. Wang and A. Kovscek 2002. A geostatistical approach to streamline-based history matching. SPE Journal 7(3): 250-266.

Web Resources:

http://sgfl.org.bd/Haripur\%20field.htm

http://www.spe.org/industry/docs/PRMS_Guidelines_Nov2011.pdf

(Manuscript received on 6 April, 2015; Revised on 23 August, 2015) 